\title{
Suicides associated with the 2008-10 economic recession in England: time trend analysis
}

\author{
(C) $(\Theta \Theta$ OPEN ACCESS
}

\author{
Ben Barr NIHR research fellow ${ }^{1}$, David Taylor-Robinson MRC research fellow ${ }^{1}$, Alex Scott-Samuel \\ senior clinical lecturer in public health ${ }^{1}$, Martin McKee professor ${ }^{2}$, David Stuckler lecturer ${ }^{23}$
}

'Department of Public Health and Policy, University of Liverpool, Liverpool L69 3GB UK; ${ }^{2}$ London School of Hygiene and Tropical Medicine, London, UK; ${ }^{3}$ Department of Sociology, Cambridge University, Cambridge, UK

\begin{abstract}
Objective To determine whether English regions worst affected by the economic recession in the United Kingdom in 2008-10 have had the greatest increases in suicides.

Design Time trend analysis comparing the actual number of suicides with those that would be expected if pre-recession trends had continued. Multivariate regression models quantified the association between changes in unemployment (based on claimant data) and suicides (based on data from the National Clinical Health Outcomes Database).

Setting 93 English regions, based on the Nomenclature of Territorial Units Statistics level 3 groupings of local authorities at county level and groups of unitary local authorities.

Participants Men and women with a record of death from suicide or injury of undetermined cause in 2000-10.

Main outcome measure Number of excess suicides during the economic recession (2008-10).

Results Between 2008 and 2010, we found 846 (95\% confidence interval 818 to 877 ) more suicides among men than would have been expected based on historical trends, and 155 (121 to 189) more suicides among women. Historically, short term yearly fluctuations in unemployment have been associated with annual changes in suicides among men but not among women. We estimated that each $10 \%$ increase in the number of unemployed men was significantly associated with a $1.4 \%(0.5 \%$ to $2.3 \%$ ) increase in male suicides. These findings suggest that about two fifths of the recent increase in suicides among men (increase of 329 suicides, 126 to 532 ) during the 2008-10 recession can be attributed to rising unemployment.
\end{abstract}

Conclusion The study provides evidence linking the recent increase in suicides in England with the financial crisis that began in 2008. English regions with the largest rises in unemployment have had the largest increases in suicides, particularly among men.

\section{Introduction}

Few would contest that the UK government's austerity policy has increased job losses, and indeed, one of its core aims has been to achieve large scale reductions in public sector employment. But what are the implications for health?

This is an important question. A recent report commissioned by the government called for measures that would make dismissing employees easier than it is now, conceding that "some people will be dismissed simply because their employer doesn't like them," but arguing that this is a "price worth paying." Although the wording of the report was unusually blunt, it reflected a widely held view among many of the government's supporters that the answer to the current financial problems was to deregulate labour markets further, with so-called "supply-side" policies that weaken employment protection and obligations in areas such as health and safety. ${ }^{2}$ But if these policies are to be pursued, what is the price that must be paid by those who will lose their jobs? Such knowledge is essential before deciding whether this price is worth paying. A growing number of people may be paying the ultimate price. In 2008, suicides began to rise in England, from a 20 year low, ${ }^{34}$ increasing by $7 \%$ among men and $8 \%$ among women from the previous year (fig $\Downarrow$ ). Although suicides began to fall again in 2010 , they are currently still above corresponding values in 2007.

But can these recent increases in suicide be attributed to the current financial crisis? ${ }^{35}$ Commentators on an observed increase in suicides in Greece argued that it was a "premature over-interpretation" to attribute this increase to the crisis, since the changes were within the range of annual statistical fluctuations, owing to the small numbers involved. ${ }^{5}$ Whether health ministers hold the same views about the trends in the UK is unclear since, as far as we know, they have been entirely 
silent about the factors that might explain the rise in suicides. However, a considerable body of research at the individual level from longitudinal studies indicates that unemployment does increase risks of suicide and non-fatal self harm..$^{6-9}$ Although suicides do tend to increase during economic downturns, ${ }^{10-13}$ the strength of the association varies among countries, and there is evidence that risks can be mitigated by strong social support and employment programmes. ${ }^{11}$ Conversely, it is possible that other factors have caused the observed rise, separate from the crisis.

Much of the previous research at population level has used aggregated data from one or more countries. ${ }^{10}{ }^{14}{ }^{15}$ These studies often had few data points, lacking statistical power to identify underlying factors. However, in large countries, it is also possible to take advantage of subnational variations, ${ }^{16}$ offering the benefit of more consistent surveillance systems and ensuring that national level factors, such as legislation changing access to the means of suicide, are kept constant. ${ }^{17}$ The current economic crisis in England has been unequally distributed across its regions. Since 2005, the West Midlands has experienced the greatest increase in unemployment (6.1 percentage points), while southeast England has had the least (2.7 percentage points). ${ }^{18}$ These regional variations provide an opportunity to assess, for the first time, whether the current recession and associated rises in unemployment are significant determinants of rising suicides in England.

In this study, we exploit these regional differences in rates of suicide and unemployment between 2000 and 2010 to test the hypothesis that those regions with greater rises in unemployment have had corresponding increases in suicides. Previous studies in the UK have sought to understand the reasons for a fall in suicides rates from high levels in the late $1990 \mathrm{~s},{ }^{19}$ although none has, to our knowledge, investigated the causes of the current increases in suicide.

\section{Methods}

Annual panel data for the number of deaths from suicides and injuries of undetermined cause were obtained from the National Clinical and Health Outcomes Database, covering the years 2000 to $2010 .{ }^{20}$ We used the start date of 2000 to compare trends over the past decade; however, we replicated our results using the first year (1993), for which data were available from the database. Deaths from undetermined injuries were included, because this category includes cases for which the coroner has given an open or narrative verdict, instead of a classification of suicide. Since there is a great deal of variation in the practice of coroners in determining suicide, we included undetermined injuries with suicides, to provide a more consistent measure of all deaths that are likely to be suicides, following conventional practice with government statistics in the UK. ${ }^{21}$ Data were available for 93 local areas, based on the Nomenclature of Territorial Units Statistics level 3 (NUTS3) groupings of local authorities at county level and groups of unitary local authorities in England. The nomenclature is a geocode standard for referencing the subdivisions of countries for statistical purposes developed by Eurostat. ${ }^{22}{ }^{23} \mathrm{Web}$ appendix 1 provides further details of the datasets.

We measured unemployment as the number of people claiming unemployment benefits within each region, using data provided by the Office for National Statistics. Although this measure does not capture all unemployment, and may understate true unemployment in a period of austerity, it is the most precise and consistent measure that is officially recorded in all regions.
Claimant data are also highly correlated with unemployment statistics $(\mathrm{r}=0.73, \mathrm{P}<0.001)$.

\section{Statistical analysis}

The statistical analysis proceeded in two steps. Firstly, we assessed the total excess number of suicides attributable to the financial crisis following standard definitions of excess, by calculating the number of suicides that were over and above historical trends. Here, we used a time trend model to estimate the "counterfactual" rate- that is, what the rate would have been had trends continued to decline at the pre-crisis rate. A dummy variable for the crisis years of 2008-10 was included in the model to capture a break from past time trends. To simplify interpretation, we modelled numbers rather than rates, although our conclusions did not change substantively when using rates. To increase precision, we modelled the excess number of suicides in the recessionary period of 2008-10, although results were similar when evaluating each year separately.

In the second step of the analysis, we assessed the association of changes in unemployment (that is, new job losses rather than long term unemployment, reflecting evidence that it is the transition in employment status that is important) with suicides, stratified by region and sex using linear regression models. At the ecological level, there is potential confounding from unobserved factors that vary between local authorities; therefore, we used a fixed effects approach to remove these between local authority differences. ${ }^{24}$ This conservative approach involves including dummy variables for each NUTS3 area to assess the association between deviations from the average rate of change in unemployment and deviations from average rate of change in suicides in each NUTS3 area. We used robust clustered standard errors to reflect the fact that populations were not sampled independently and to ensure that standard errors were robust to serial correlation in the data. Models were used to estimate the suicides attributable to changes in unemployment in the 2008 recession. All data and models were estimated using Stata version 12 .

\section{Results}

\section{Total excess suicides during the recession}

Before the economic crisis in 2008, the rate of male suicides was declining in England by 57 suicides per year (95\% confidence interval 56 to 58), from 2000 to 2007; female suicides decreased by 26 suicides per year (24 to 27 ) in the same period (table $1 \Downarrow$ ). We estimated 846 more suicides among men ( 818 to 877 ) and 155 more suicides among women (121 to 189 ) than would have been expected if these trends had continued in the period 2008-10.

\section{Annual associations of suicides with unemployment by sex and region}

As depicted in the figure, and as is evident across English regions, levels of unemployment correlated strongly with suicides among men and women in the period studied $\left(\mathrm{r}_{\text {male }}=0.73\right.$, $\left.\mathrm{P}<0.001 ; \mathrm{r}_{\text {female }}=0.68, \mathrm{P}<0.001\right)$. To assess the specific effect of job losses during the recession, rather than long term unemployment, we evaluated short annual changes in unemployment. Table $2 \Downarrow$ shows the associations between short term changes in job losses and suicides. Between 2000 and 2010 , each annual $10 \%$ increase in the number of unemployed men was associated with a $1.4 \%$ increase in the number of male suicides ( $95 \%$ confidence interval $0.5 \%$ to $2.3 \%$ ). Among 
women, however, these short term associations were not significant $(0.7 \%$ increase, $-1.5 \%$ to $3.0 \%)$.

With our estimates of total excess suicides and the association between unemployment and suicide rates, we estimated the portion of excess suicides attributable to unemployment. Relative to 2007, the number of unemployed men rose on average across English regions by 25.6\% each year in 2008-10. Based on our models, this increase in unemployment was associated with yearly increases in male suicides of $3.6 \%$. This percentage rise corresponds to 329 ( $95 \%$ confidence interval 126 to 532) additional suicides between 2008 and 2010, accounting for about two fifths of the total excess suicides among men during the recession.

\section{Robustness tests}

To determine whether the association between unemployment and suicides in the recessionary period differed from past trends during periods of economic growth, models were disaggregated by time period. The significant association between unemployment and suicides among men remained after we analysed separately data from 2006 to 2010 (when unemployment was rising) and before 2006 (when unemployment was falling; web appendix 4). We saw no significant difference in the size of association during these two periods (test for effect heterogeneity, $\mathrm{P}=0.35$ ).

We tested the robustness of our estimates using alternative assumptions: removing observations with large year-to-year fluctuations in suicides (>150\%); fewer than 10 suicides per year; and standardised residuals of an absolute value greater than 2. None of the re-estimated results changed under these assumptions. Since the variance in the change in suicide rates depends on the number of suicides in each area, we also estimated models using weights for the annual mean number of suicides in each area. Again, none of the results changed. Unadjusted associations yielded stronger effects (web appendix 2). Lastly, we investigated lead and lagged effects in the first and second year, finding no significant effects (web appendix 3 ). We also did statistical models without adjusting for time trends and used the longest time series available from 1993, finding similar results (web appendix 4). Estimated associations of unemployment with suicides were similar after excluding undetermined injuries from suicide calculations (web appendix $5)$.

\section{Discussion}

Our study estimated that the recent recession in the UK has led to about 1000 excess suicides in England: 846 among men and 155 among women. Our analysis indicates that increases in male unemployment were associated with about two fifths of these rises in suicides among men in England during the current recession. Local areas with greater rises in unemployment have also experienced higher rises in suicides, although this level was significant only among men, possibly because the suicide rates among women are only about a third of those among men. On its own, our study cannot ascertain whether the association between job loss and suicides is causal; however, the strength of the effect size, timing, consistency, coherence with previous research, existence of plausible mechanisms, and absence of any obvious alternative explanation suggest that it is likely to be. ${ }^{25}$ Importantly, these findings can explain why there was a small reduction in suicides in 2010 , which coincided with a slight recovery in male employment.

\section{Limitations of the study}

Before evaluating the implications of our findings, we must note several important limitations. Firstly, we undertook an observational analysis at the population level; however, in contrast with previous work, we were able to take advantage of subregional variations in unemployment and suicide rates. Nonetheless, the analysis of subregional data still cannot account for potential differences across employed and unemployed groups, and results could indicate increasing risks among both groups during economic downturns (for example, as a consequence of uncertainty about the future among employed people). Furthermore, within local areas, there may be differences in the share of the population most vulnerable to the effects of unemployment, such as people with low levels of education or with pre-existing mental health problems. ${ }^{86}$

Secondly, we measured unemployment using the number of claimants, which could underestimate the true number of people who cannot find work. To claim unemployment benefits, people must meet certain criteria, such as be capable of work, be available for work, actively seek work, as well as fulfilling contributory or means testing requirements. Thus, some people may leave the employment market altogether rather than attempt to claim benefits. ${ }^{27}$ Alternative measures, such as the Labour Force Survey, would not provide sufficiently detailed data for geographical analysis.

Thirdly, suicides measure a very small portion of the overall health consequences of unemployment. ${ }^{28}$ Fourthly, analysis of suicides in small areas must be interpreted with caution because of the varying use of narrative verdicts by coroners and the difficulties in translating coroners' verdicts into codes according to the International Classification of Diseases. ${ }^{21}$ However, our inclusion of injuries of undetermined cause should have largely dealt with this problem, and such biases are probably relatively constant over time, making estimates of changes within regions more consistent for testing our study's hypothesis. Finally, our estimates of the risks of suicides attributable to unemployment were based on the contemporary period, because we did not observe significant lead or lagged effects.

\section{Policy implications}

Our analysis, coupled with evidence from other studies, ${ }^{11}$ has several implications for those seeking to protect the most vulnerable people in the ongoing economic recession. Firstly, our study indicates that although the initial economic shock of recession does increase suicide risk, policies that promote re-employment could reverse this trend. However, forecasts for economic growth over the next 10 years in the UK indicate that employment is unlikely to return to levels before the recession until after $2017 .{ }^{29}$ Overall, women seem less likely to inflict self harm in response to unemployment, suggesting an increased degree of resilience among women, which has been identified in other European countries..$^{30}$ Our study may have lacked sufficient power to detect an effect in women, if this effect size was small. An enhanced understanding of the role of responses from each sex may help mitigate risks. However, more research is needed to understand why suicides have risen recently among women, in view of the absence of an association with their employment.

Secondly, budget cuts could exacerbate the consequences of the ongoing economic recession, both by increasing losses of public sector jobs (and those in the private sector that they support) and by reducing access to preventive services. Austerity measures in the UK are exacerbating unemployment and reducing growth, ${ }^{31}$ and some commentators have suggested that 
the government should promote employment, particularly in deprived areas, through state led social investment in infrastructure, industry, education, early years support, and improved working conditions. ${ }^{32}$ Cuts to local authority budgets in England have been greatest in more disadvantaged areas ${ }^{33}$ with higher suicide rates. Recent increases in unemployment between 2010 and 2011 are also significantly correlated with local authority budget cuts (correlation coefficient between reduction in spend per head of population and increase in male claimant rate, $\mathrm{r}=-0.21, \mathrm{P}=0.0026$; authors' calculations).

Unemployment and the unequal economic recovery in England are pressing public health issues. ${ }^{34}$ The total cost of suicide in Ireland, for example, was estimated to be about $1 \%$ of the country's gross domestic product in $2002 .{ }^{35}$ There is a danger that the human cost of continued high levels of unemployment will outweigh the purported benefits of budget cuts.

Contributors: BB and DTR collected the data and originated the study. $\mathrm{BB}, \mathrm{DS}$, and DTR contributed to the analysis and interpretation of the data. All authors contributed to the writing of the manuscript. BB is the study guarantor.

Funding: BB is supported by a National Institute of Health Research fellowship and DTR is supported by a Medical Research Council fellowship.

Competing interests: All authors have completed the Unified Competing Interest form at www.icmje.org/coi_disclosure.pdf (available on request from the corresponding author) and declare: no support from any organisation for the submitted work; no financial relationships with any organisations that might have an interest in the submitted work in the previous three years; no other relationships or activities that could appear to have influenced the submitted work.

Ethical approval: Ethical approval not required.

Data sharing: The dataset used for the analysis and statistical code are available from the corresponding author at benbarr@liverpool.ac.uk.

1 Beecroft A. Report on employment law. UK Department for Business Innovation \& Skills, 2011.

2 White M. Liam Fox's deregulation remedy? Another tonic we don't need. The Guardian 2012

3 Stuckler D, Basu S, Suhrcke M, Coutts A, McKee M. Effects of the 2008 financial crisis on health: a first look at European data. Lancet 2011;378:124-5.

4 Economou M, Madianos M, Theleritis C, Peppou L, Stefanis C. Increased suicidality amid economic crisis in Greece. Lancet 2011;378:1459.

5 Fountoulakis K, Grammatikopoulos I, Koupidis S, Siamouli M, Theodorakis P. Health and the financial crisis in Greece. Lancet 2012;379:1001-2.

6 Platt S, Hawton K. Suicidal behaviour and the labour market. In: Hatwon K, Van Heeringen $\mathrm{K}$, eds. International handbook of suicide and attempted suicide. John Wiley and Son, 2000.

7 Blakely T, Collings S, Atkinson, J. Unemployment and suicide: evidence for a causal association? J Epidemiol Community Health 2003;57:594-600.
8 Lundin A, Lundberg I, Hallsten L, Ottosson JTH. Unemployment and mortality: a longitudinal prospective study on selection and causation in 49321 Sweden middle aged men. J Epidemiol Community Health 2010;64:22-8.

9 Lewis G, Sloggett A. Suicide, deprivation and unemployment: record linkage study. BMJ 1998;317:1283-6.

10 Chang S, Gunnell D, Sterne J, Lu T, Cheng A. Was the economic crisis 1997-1998 responsible for rising suicide rates in East/Southeast Asia? A time-trend analysis for Japan, Hong Kong, South Korea, Taiwan, Singapore and Thailand. Soc Sci Med 2009;68:1322-31.

11 Stuckler D, Basu S, Suhrcke M, Coutts A, McKee, M. The public health impact of economic crises and alternative policy responses in Europe. Lancet 2009;374:315-23.

12 Luo F, Florence CS, Quispe-Agnoli M, Ouyang L, Crosby AE. Impact of business cycles on US suicide rates, 1928-2007. Am J Public Health 2011;101:1139-46.

13 Noh Y. Does unemployment increase suicide rates? The OECD panel evidence. J Econ Psychol 2009;30:575-82.

14 Ruhm C. Macroeconomic conditions, health and government policy. In: Schoeni R, House JS, Kaplan GA, Pollack H, eds. Making Americans healthier: social and economic policy as health policy. Russell Sage, 2008.

15 Tapia-Granados J. Recessions and mortality in Spain, 1980-1997. Eur J Population 2005;21:393-422.

16 Stuckler D, Basu S, Meissner C, Fishback P, McKee M. Banking crises and mortality during the Great Depression: evidence from US urban populations, 1927-1939. J Epidemiol Community Health 2011;66:410-9.

17 Hawton K, Bergen H, Simkin S, Arensman E, Corcoran P, Cooper J, et al. Impact of different pack sizes of paracetamol in the United Kingdom and Ireland on intentional overdoses: a comparative study. BMC Public Health 2011:11:460-7.

18 Office of National Statistics. South and East of UK escaped the worst of unemployment increases since 2005 . ONS, 2011.

19 Biddle L, Brock A, Brookes S, Gunnell D. Suicide rates in young men in England and Wales in the 21st century: time-trend study. BMJ 2008;336:539-42.

20 NHS Information Centre. Compendium of population health indicators. National Centre for Health Outcomes Development, 2011.

21 Carroll R, Hawton K, Kapur N, Bennewith O, Gunnell D. Impact of the growing use of narrative verdicts by coroners on geographic variations in suicide: analysis of coroners' inquest data. J Public Health 2011: published online 15 November.

22 Office for National Statistics. NOMIS-official labour market statistics, 2011. ONS, 2011.

23 EuroStat. Nomenclature of territorial units for statistics. European Commission, 2008.

24 Jones A. Health econometrics. In: Cuyler A, Newhouse JP, eds. Handbook of health economics. Elsevier Science, 2000:265-344.

25 Bradford-Hill A. The environment and diseases: association or causation? Proc $R$ Soc Med 1965;58:295-300

26 Edwards R. Who is hurt by procyclical mortality? Soc Sci Med 2008;67:2051-8.

27 Gregg P. Out for the count: a social scientist's analysis of unemployment statistics in the UK. J R Stat Soc A 1994;157:253-70.

28 Bartley M. Unemployment and ill health: understanding the relationship. J Epidemiol Community Health 1994;48:333-7.

29 Office for Budget Responsibility. Economic and fiscal outlook. OBR, 2011.

30 Hadju P, McKee, M, Bojan, F. Changes in premature mortality differentials by marital status in Hungary and in England and Wales. Eur J Publ Health 1995;5:259-64.

31 Ball L, Leigh D, Loungani P. Painful medicine. Finance \& Development 2011;48:20-3. www.imf.org/external/pubs/ft/fandd/2011/09/Ball.htm.

32 Lawson N, Reed H, Plan B. A good economy for a good society. Compass, 2011.

33 Taylor-Robinson D, Gosling R. Local authority budget cuts and health inequalities. BMJ 2011;342:d1487.

34 Marmot M. Fair society, healthy lives. UCL, 2010.

35 Kelly B. The economic cost of suicide in Ireland. J Crisis Intervention Suicide 2007;28:89-94.

Accepted: 13 July 2012

\section{Cite this as: BMJ 2012;345:e5142}

This is an open-access article distributed under the terms of the Creative Commons Attribution Non-commercial License, which permits use, distribution, and reproduction in any medium, provided the original work is properly cited, the use is non commercial and is otherwise in compliance with the license. See: http://creativecommons.org/licenses/by$\mathrm{nc} / 2.0 /$ and http://creativecommons.org/licenses/by-nc/2.0/legalcode. 


\section{What is already known on this topic}

In 2008, suicide rates began to rise in the United Kingdom, reversing a long term decline

It is not clear whether this increase can be attributed to the economic recession of 2008-10

\section{What this study adds}

English regions with the largest rises in unemployment have shown the largest increases in suicides, particularly among men

\section{Tables}

Table 1 | Time trend analysis of excess suicides during the economic recession in 2008-10, by sex

\begin{tabular}{lcc} 
& \multicolumn{2}{c}{ No of excess suicides $(95 \%$ Cl) } \\
\cline { 2 - 3 } Covariate & Male suicides & Female suicides \\
Expected annual trend, $2000-10$ & $-57(-56$ to -58$)$ & -26 ( -24 to -27$)$ \\
\hline Estimated excess suicides during recession, $2008-10^{*}$ & $846(818$ to 877$)$ & 155 (121 to 189$)$ \\
\hline
\end{tabular}

${ }^{*}$ Calculated as the difference between observed and expected suicides if time trends in 2000-07 had continued during 2008-10. 
Table 2| Association of unemployment with suicide rates (\%) in 93 local areas of England in 2000-10, by sex

\begin{tabular}{lccc} 
& \multicolumn{3}{c}{ Suicide rate $(95 \% \mathrm{Cl})$} \\
\cline { 2 - 3 } $10 \%$ rise in no of male claimants & Male & Female \\
\hline $10 \%$ rise in no of female claimants & $1.4^{*}(0.5$ to 2.3$)$ & - \\
\hline
\end{tabular}

Model based on evaluating changes in suicide rates against changes in unemployment, adjusted for region specific time trends. No of local area years was 1023 among men and 1017 among women.

${ }^{*} \mathrm{P}<0.001$. 


\section{Figure}
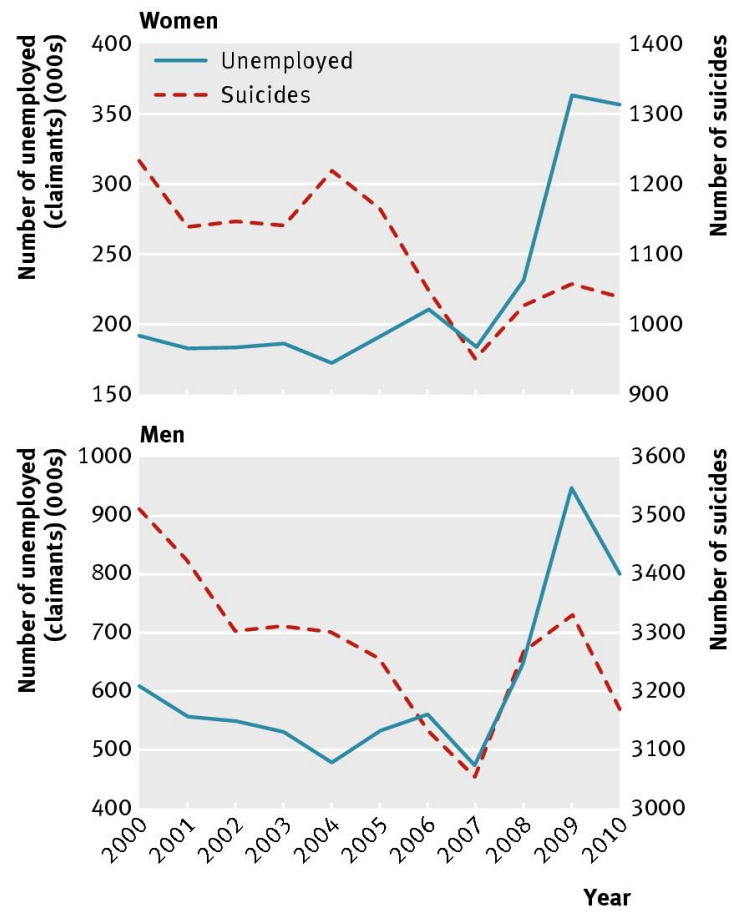

Trends in the numbers of suicides and unemployment claimants in England, 2000-10, by sex 